\title{
An Innovative Shape of Geogrid to increase Pull-Out Capacity
}

\author{
Islam Anas ${ }^{1}$, Ahmed Farouk ${ }^{2}$, M. B. El Sideek ${ }^{3}$, A-R. Hassan ${ }^{4}$, Yousry \\ Mowafy $^{5}$ \\ ${ }^{I}$ MSc. Student, Department of Civil Engineering, Al-Azhar University, Cairo, Egypt \\ ${ }^{2}$ Assistant Professor, Department of Civil Engineering, Tanta University, Tanta, Egypt \\ ${ }^{3,4}$ Assistant Professor, Department of Civil Engineering, Al-Azhar University, Cairo, Egypt \\ ${ }^{5}$ Professor, Department of Civil Engineering, Al-Azhar University, Cairo, Egypt
}

\begin{abstract}
In this research, the philosophy of manufacturing the geogrids in their conventional shape is modified to let the friction between the ribs and soil particles have a noteworthy effect on the final resistance of soil reinforced by geogrids. Inspired by the belts used to link gears, both surfaces of the conventionalBiaxial Geogridwere reformed by adding cubic cogs distributed in a sine wave order on both sides of the ribs. The proposed geogrid shall be denominated "ICB-GGR" as an abbreviation for Isometric Cogged Biaxial Geogrid. In order to study the improvement in the soil-cogged geogridinteraction, prototypes of theconventional Biaxial geogrid and the modified ICB-GGR were manufactured of steel 37with the same dimensions of apertures and ribs. After many unsucccessful trials to manufacture polymeric geogrid prototypes due to some technical difficulties, steel 37 was the most appropriate material to accomplish the researchsince the main target isto investigate theshapeeffect of the proposed ICB-GGR.Pull-out tests were operated according toASTM D 67060101with some modifications to suit the laboratory preparations.The geogrid prototypes were used to reinforce uniformly graded sand and were tested under three different values of overburden pressures. The results showed that thepull-out resistance of the proposed ICB-GGR superior the conventional Biaxial Geogrid by about 50\%.
\end{abstract}

Keywords:Biaxial Geogrid, Cogged Geogrid,ICB-GGR, laboratory tests,Sand, Pull-out test, Pull-out resistance, Loading frame, prototypes.

\section{Introduction}

Since late 1970s, when geogrids were invented by Dr. Brian Mercerin the UK (Shukla and Yin, 2006) [1],the shape of geogrids in their different types have the same unchanged design characteristics. They have been always consisting of small surface areas and large apertures, giving the geogrid a main function of confinement. Giroud (2009) [2] stated that the focus for research, development and practical design should shift towards developing better understanding of the composite materials created by the combination of geogrids and soils. To derive high benefit from this combination, it is perefable to use soil with big particles as the geogrid filling material since the passive strength developed by the big particles against geogrid increases the interlocking effect. Pinto (2003) [3] reported that an exception occurs when the soil particles are small as the interlocking effect is negligible because no passive strength is developed against the geogrid.

In this research, the exception mentioned by Pinto (2004) [3] is expelled as the conventional shape of BiaxialGeogrid is modified by distributing cubic cogs on both sides, letting the small particles of soil develop a cosiderable passive strength against geogrid, andincreasingthe interlocking between the particles and the cogs so that the interlocking effect between geogrid and the small soil particles is no more negligible.

In the light of the researches of investigating the soil-reinforcement interaction using pull-out laboratory tests done by Senoon and Farghal(2003), Duszynska and Bolt (2004), Koerner (2005),Abdel-Rahman et al. (2007), Hsieh et al. (2011), Moraci and Cardile (2012), and Mosallanezhad et al. (2016) [4, 5, 6, 7, 8, 9and 10], the soil-geogrid interaction was investigated using means of pull-out laboratory tests.

At the early stages of this research, there were many attempts to manufacture the proposed ICB-GGR from a polymeric material. Unfortunately, these attempts did not succeed due to some technical defficulties. Accordingly, the studied prototypes of the ICB-GGR and the Biaxial Geogrid were decided to be made of steel 37. Hence, the comparisonheld in this research shall be focusing mainly on the effect of changing the geogrid's shape on the pull-out resistance. The prototype of the Biaxial Geogridused in this study waspunched out of $0.2 \mathrm{~cm}$ thickness steel plate using a laser cutter machine.However, there was no availability to manufacture theICB-GGR using the same procedure. Consequently,steel ribs with cubic cogs were cut individually by the same laser machine and were welded at the junctions using the TIG welding technique.In this research, thepullout tests were carried out underdifferent values of overburden loads to measure the improvment in the shearing resistance, the interlocking and the improved soil characteristics due to reinforcing the soil with the new proposedICB-GGR. 


\subsection{Equipments}

\section{Laboratory Pull-Out Tests}

Pull-out tests were operated according to ASTM D 6706-0101 [11] with some modifications to suit the laboratory preparations. The pull-out test box and the loading frame used in this research to study the soilgeogrid interaction are illustrated in Fig.(1). The inner dimensions of the steel box are $100 \mathrm{~cm}$ (length) $\times 70 \mathrm{~cm}$ (width) $\times 70 \mathrm{~cm}$ (height). Two L-angels were welded parallel to the front face performing an edge channelto accomodate 6 wooden plates having a thickness of $2.5 \mathrm{~cm}$ which represented a retaining wall for the tested soil. At a height of $30 \mathrm{~cm}$, an opening of $60 \mathrm{~cm}$ (width) $\times 2 \mathrm{~cm}$ (height) was provided at the front of the box to facilitate the pulling out of the geogrids. Asteel channel clamp was utilized for holding the geogrid and was fixed to the geogrid by 12 bolts as shown in Fig. (2). The vertical stress was applied by a manually-controlled hydraulic jack having the capacity of $1000 \mathrm{kN}$ and was placed on the steel plate. A steel frame, as shown in Fig. (3),was mounted over the pull-out box to give the required reaction. Overburden load was uniformly distributed by placing a steel plate that has dimentions of $73 \mathrm{~cm}$ (length) $\times 49 \mathrm{~cm}$ (width) $\times 4 \mathrm{~cm}$ (depth). A manuallycontrolled hydraulic jack having a capacity of $230 \mathrm{kN}$ was used for applying thepull-out load. The pull-out load was applied to the geogrid via a steel wire attached to the clamp and the reaction was taken from the ground by a steel frame mounted in front of the pull-out box. The front displacementsweremeasured using twodialgaugesso that average values can be calculated.
1 - Steel frame
2 - Hydrauligack
3 - Steel plate
4 - Wooden plates
5 - Clamping plate
6- Steel wire
7 - Dial gauge
8 - Geogrid
9 - Supporting system

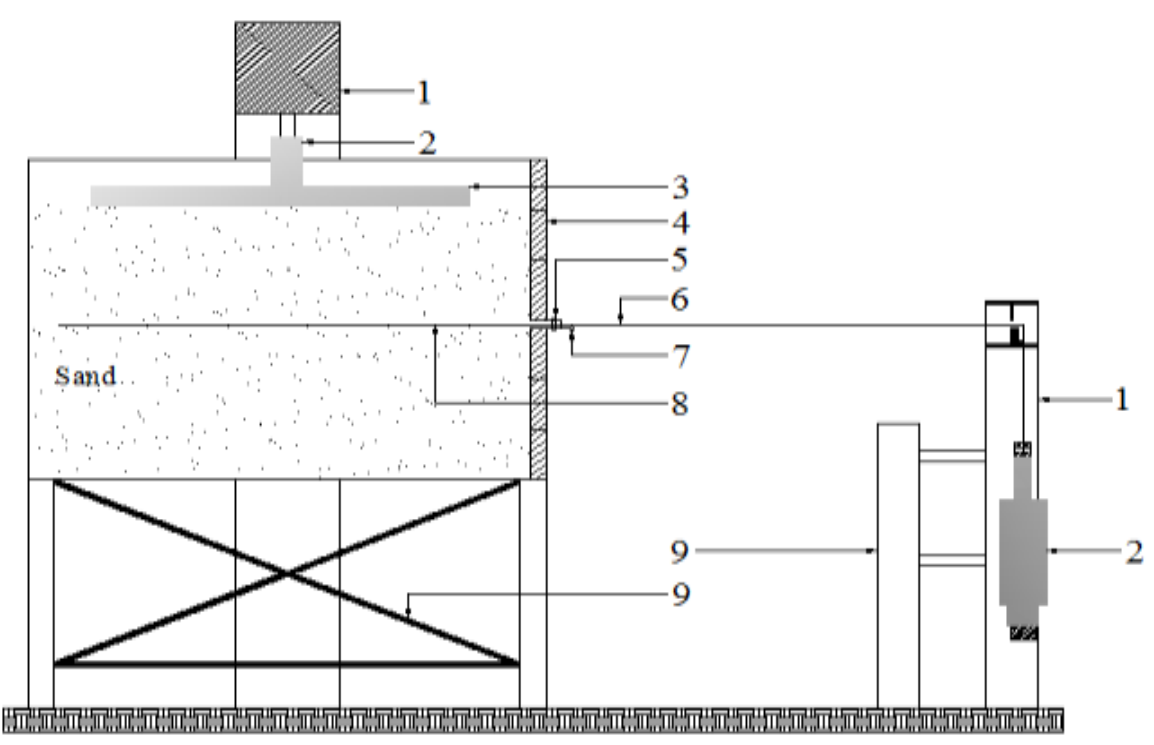

Figure (1): Schematic diagram of the pull-out testing device.

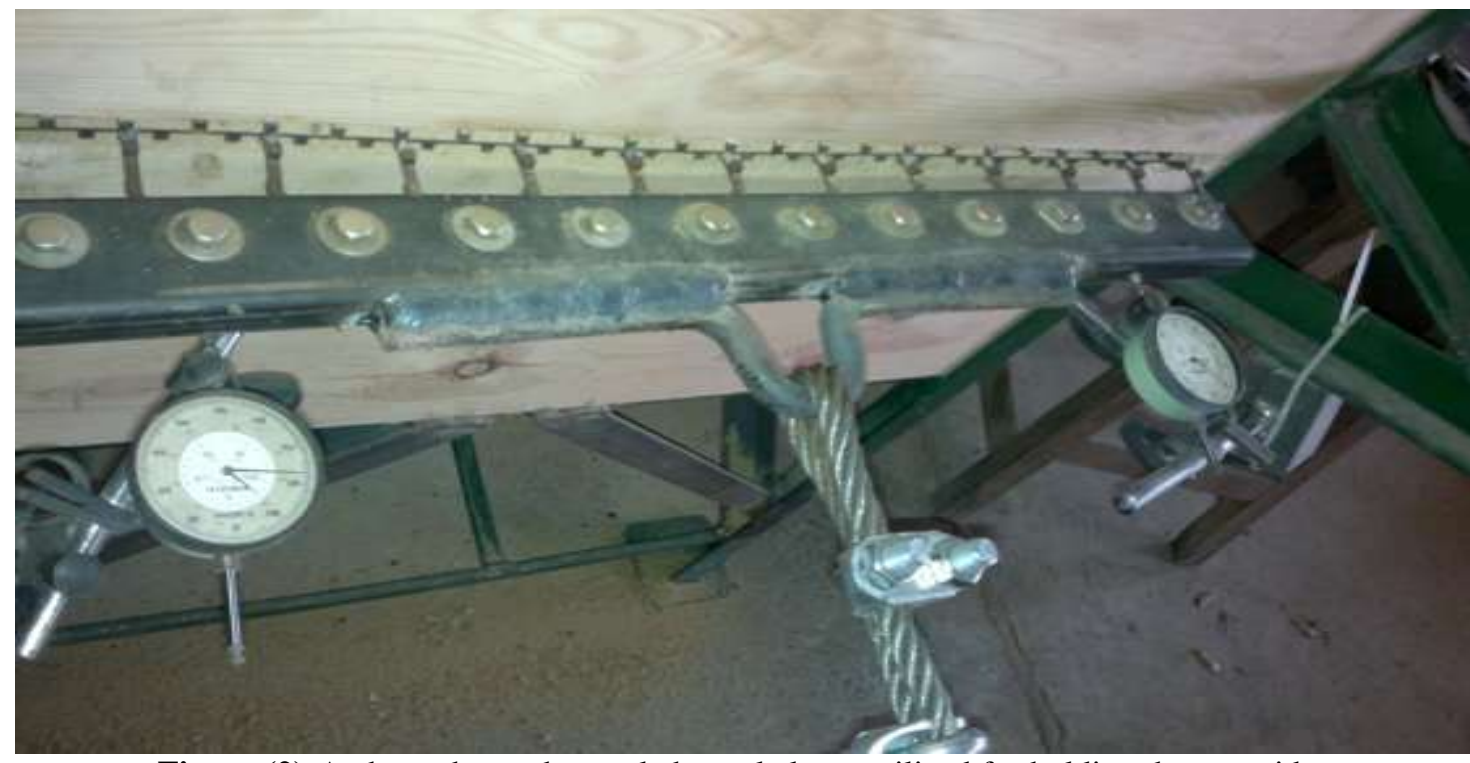

Figure (2): A photo shows the steel channel clamp utilized for holding the geogrids. 


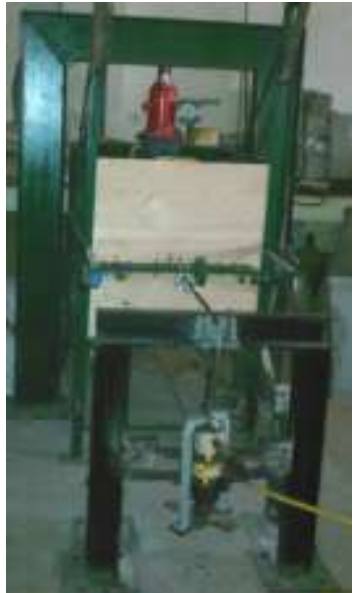

Figure (3): An overall view of the pull-out testing device used in the current study.

\subsection{Materials}

Materials branch into soil and geogrids. Properties of both of them will be illustrated next.

\subsubsection{Soil}

In this research, uniformly graded sand was used in its loose state. Fig. (4) shows the distribution of sand particles. On the beginning, series of laboratory tests were conducted to obtain the basic physical properties of the sand. The tests showed that the used sand in its loose state has a dry density of $16 \mathrm{kN} / \mathrm{m}^{3}$, auniform coefficient $\mathrm{C}_{\mathrm{u}}$ of 2.6, and aninternal friction angle $\varphi$ of $28^{\circ}$.

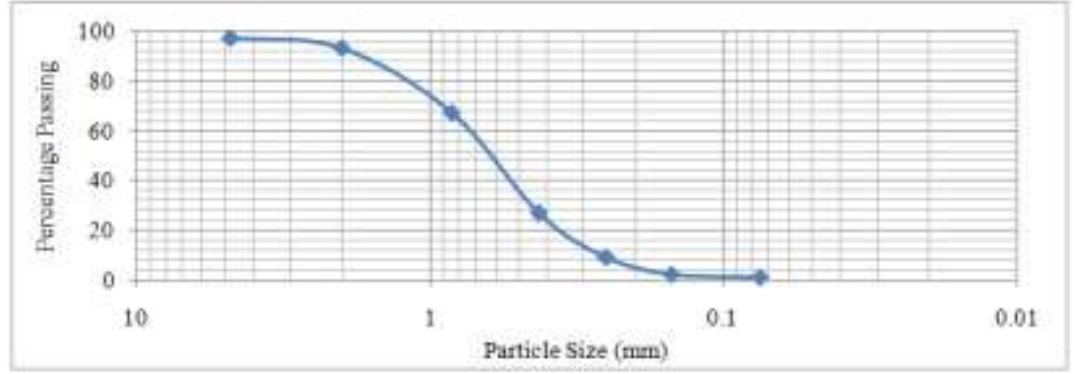

Figure (4): Particle size distribution of sand.

\subsubsection{Geogrids}

The prototypes of geogrids used in this studywere all manufactured of steel 37 and had the same outer dimensions of $100 \mathrm{~cm}$ (length) $\times 60 \mathrm{~cm}$ (width) as shown in Fig. (5). The first prototypewas a Solid Plate having a thickness of $0.2 \mathrm{~cm}$ and it was used to represent the control case of the research. The second prototype was manufacture to representa conventional commercial BiaxialGeogrid with aperture sizeof5 $\mathrm{cm} \times 5 \mathrm{~cm}$ and a thickness of $0.2 \mathrm{~cm}$. The last prototypewas the ICB-GGR withaperture size of $5 \mathrm{~cm} \times 5 \mathrm{~cm}$ and a rib thickness of $0.2 \mathrm{~cm}$, in addition to $0.5 \mathrm{~cm} \times 0.5 \mathrm{~cm} \times 0.5 \mathrm{~cm}$ cubic cogs, as shown in Figs. (5), and (6)

Both the Solid Plate and the Biaxial Geogrid were formed from a solid steel sheetby using a laser cutter. The ICB-GGR was manufacturedof prefabricated steel ribs having cubic cogs and was assymbled, as shown in Fig. (7), to give the final geogrid shape by means ofTIG welding technique.

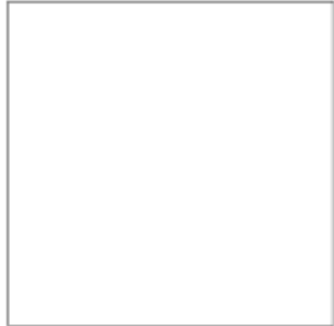

a)

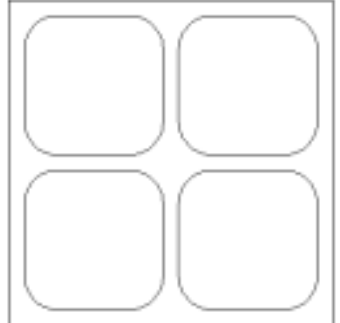

b)

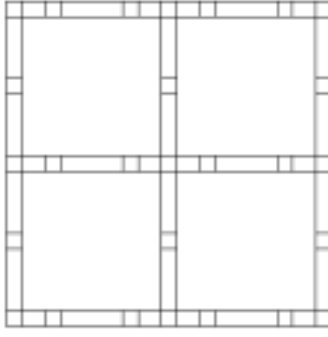

c)

Figure (5):The tested prototypes, a) SolidPlate; b)Biaxial Geogrid; c) ICB-GGR. 


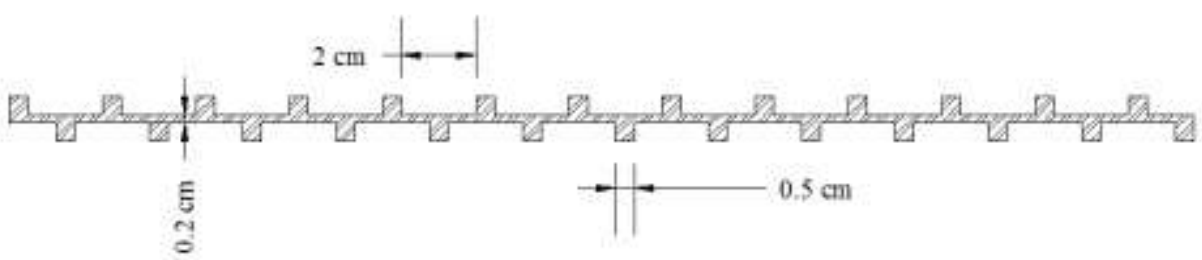

Figure (6): A section side view shows the distribution of the cogs on the ribs.

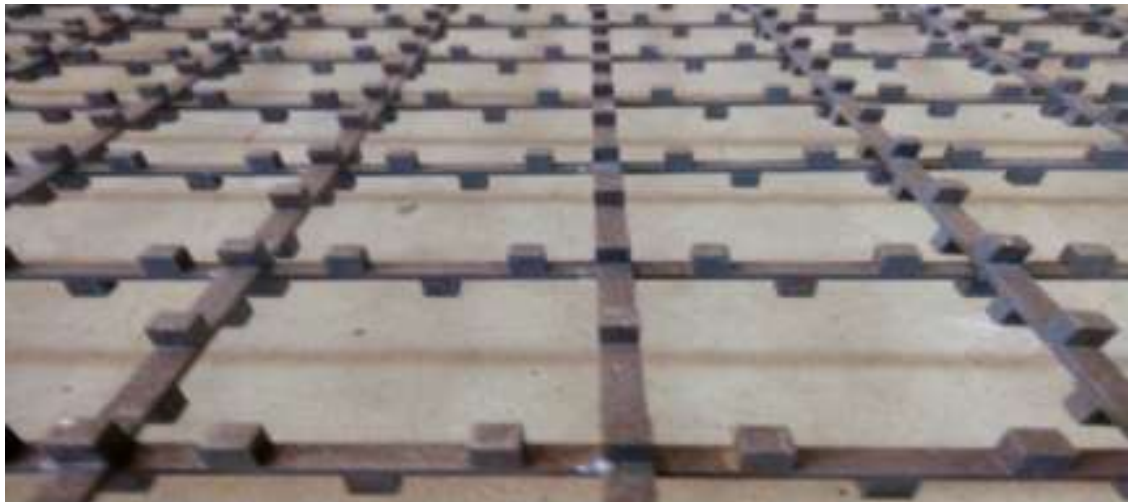

Figure (7): A photo of the proposed ICB-GGR.

\subsection{Test Cases of Loading}

Nine tests were conducted to investigate the influence of modifying the geogrid shape on the soilgeogrid interaction characteristics, especially the shear resistance. Each prototype ofthe geogrids was tested underthree different overburden pressures; (q) of $27.25 \mathrm{kN} / \mathrm{m}^{2}, 54.5 \mathrm{kN} / \mathrm{m}^{2}$ and $81.75 \mathrm{kN} / \mathrm{m}^{2}$. An exception happened when testing the ICB-GGR under the overburden pressure $54.5 \mathrm{kN} / \mathrm{m}^{2}$, as the acting force on the welded connections exceeded the safe value against rapture. The overburdenpressure (q) of $18.8 \mathrm{kN} / \mathrm{m}^{2} \mathrm{was}$ choosen to be the third value acting on the ICB-GGR. Thetotal normal stress $\sigma_{\mathrm{n}}\left(\mathrm{kN} / \mathrm{m}^{2}\right)$ acting on the geogridsis calculated using the following equation:

$$
\boldsymbol{\sigma}_{\mathbf{n}}=\gamma \mathbf{h}+\mathbf{q}
$$

Where $\gamma\left(\mathrm{kN} / \mathrm{m}^{3}\right)$ is the soil dry density; $\mathrm{h}(\mathrm{m})$ is the height of soil above thegeogrid; and $\mathrm{q}\left(\mathrm{kN} / \mathrm{m}^{2}\right)$ is the applied externalsurcharge.

\subsection{Test Procedures}

In all cases of loading, the sand was prepared inside the testing box in its loose state. It was poured manually, and placed in 6 layers with $10 \mathrm{~cm}$ thickness of each layer. When the sand reached $30 \mathrm{~cm}$ of height, the geogrid was fixed to the clamping plateand was placed over the surface of the sand. Thereafter, the restheight of the sand was completed also in three layers. Dial gauges were placed tangent to the clamping plate to measure the front displacements. The external surcharge was applied and kept constant using a hydraulic jackresting over a steel plate on the sand. After that, the pull-out load was applied incrementally in stages until failure. The applied pull-out load was kept constant between each two successive increments either for 5 minutes or till the gauges settle, whichever was longer.

\subsection{Test Results}

Table (1) shows a summary of the results obtained from the pull-out tests. In the Table, the letter (q)denotes the external surcharge, $\left(\sigma_{n}\right)$ denotes the normal stress acting on the geogrid, $(\mathrm{P})$ denotesthe pull-out load measured in the test, $(\mathrm{Q})$ is the pull-out resistance, $\left(\tau_{\mathrm{ult}}\right)$ is the interface shear strength,and (Avg. $\left.\gamma_{\text {resulted }}\right)$ is the average density of all layers measured after installing thegeogrids. The tensile strength of Tungsten, the welding material, is $1.725 \mathrm{kN} / \mathrm{mm}^{2}$. The maximum tensile force for each connection $\left(\mathrm{T}_{\mathrm{s}}\right)$ is given by:

$\mathrm{T}_{\mathrm{s}}=$ tensile strength $\times$ effective throat thickness of weld in mmxeffective length of weld in mm.

The allowable design force for each welded connection $\left(\mathrm{T}_{\mathrm{d}}\right)$ is calculated from:

$$
\mathrm{T}_{\mathrm{d}}=\frac{\mathrm{T}_{\mathrm{S}}}{\text { Factor of safety }}
$$

Taking into consideration that the factor of safety against rapture is 1.5 and the effective throat thickness of weld equal the effective length of weld equal $3 \mathrm{~mm}$. The calculated value of $\mathrm{T}_{\mathrm{s}}$ is $15.53 \mathrm{kN}$ and the value of $\mathrm{T}_{\mathrm{d}}$ is $10.35 \mathrm{kN}$. The value of the force acting on the welded connectionswhen testing the ICB-GGR 
under the overburden pressure of $54.5 \mathrm{kN} / \mathrm{m}^{2}$ was $10.94 \mathrm{kN}$.In order to protect the ICB-GGR from rapture, the less value of $18.8 \mathrm{kN} / \mathrm{m}^{2}$ was chosen to be the third overburden pressure value acting on the ICB-GGR. The general form of the interface shear strength can be defined as:

$$
\tau_{\text {ult }}=\frac{\mathrm{P}}{2 \mathrm{~A}}
$$

Where $\mathrm{P}(\mathrm{kN})$ is the pullout load, and $\mathrm{A}\left(\mathrm{m}^{2}\right)$ is the geogrid surface area. Based on the values of interface shear resistance and normal stress, the friction angle of the soil-geogrid interface $\delta\left(^{\circ}\right)$ is calculated as follows:

$$
\tan \delta=\frac{\tau_{\mathrm{ult}}}{\sigma_{\mathrm{n}}}
$$

The friction factor characterizing the soil-geogrid interaction $\alpha$ is determined as follows:

$$
\alpha=\frac{\tan \delta}{\tan \varphi}
$$

Where $\tau_{\text {ult }}\left(\mathrm{kN} / \mathrm{m}^{2}\right)$ is the interface shear resistance, $\sigma_{\mathrm{n}}\left(\mathrm{kN} / \mathrm{m}^{2}\right)$ is the total normal stress acting on the geogrid surface, and $\varphi\left({ }^{\circ}\right)$ is the angle of internal friction of the soil.According to the draft of European Standard prEN 13738 Geotextiles and related products - Determination of pullout resistance [12], the pull-out resistance (Q) of geogrid can be calculated as follows:

$$
Q=\frac{P n_{g}}{N_{g}}
$$

WhereQ $(\mathrm{kN} / \mathrm{m})$ is the pull-out resistance, $\mathrm{P}(\mathrm{kN})$ isthe pull-out load measured in the test, $\mathrm{n}_{\mathrm{g}}$ is the number of ribs per unit width of the geogrid in the direction of thepull-out load, and $\mathrm{N}_{\mathrm{g}}$ is the number of ribs of geogrid in the direction of thepull-out load.Since the Solid Plate does not have any ribs, the pull-out resistance of it is calculated as follows:

$$
\mathrm{Q}=\mathrm{P} / \text { width of Solid Plate }
$$

It is to be noted that during the tests conducted on both the Biaxial Geogrid and the SolidPlate, the pullout test box was fixed horizontally to the reaction frame in order to prevent any movement of the box. However,

\begin{tabular}{|c|c|c|c|c|c|c|c|c|}
\hline $\begin{array}{c}\mathrm{q}\left(\mathrm{kN} / \mathrm{m}^{2}\right) \\
(1)\end{array}$ & $\begin{array}{c}\sigma_{\mathrm{n}}\left(\mathrm{kN} / \mathrm{m}^{2}\right) \\
(2)\end{array}$ & $\begin{array}{c}\text { Type of GGR } \\
\text { (3) }\end{array}$ & $\begin{array}{c}\mathrm{P}(\mathrm{kN}) \\
(4) \\
\end{array}$ & $\begin{array}{l}\text { Max. Disp. } \\
(\mathrm{mm}) \\
(5)\end{array}$ & $\begin{array}{c}\mathrm{Q} \\
(\mathrm{kN} / \mathrm{m}) \\
(6)\end{array}$ & $\begin{array}{c}\text { Avg. } \\
\gamma_{\text {resulted }} \\
(7)\end{array}$ & $\begin{array}{c}\tau_{\mathrm{ult}} \\
\left(\mathrm{kN} / \mathrm{m}^{2}\right) \\
(8) \\
\end{array}$ & $\begin{array}{l}\text { Mode of } \\
\text { failure } \\
\text { (9) }\end{array}$ \\
\hline \multirow[t]{2}{*}{27.25} & \multirow[b]{2}{*}{33.61} & Solid Plate & 19.62 & 22.345 & 32.7 & 16.72 & 16.35 & slippage \\
\hline & & $\begin{array}{c}\text { Biaxial } \\
\text { Geogrid }\end{array}$ & 58.86 & 26.11 & 95.08 & 16.82 & 49.05 & slippage \\
\hline \multirow[t]{3}{*}{54.5} & \multirow{3}{*}{60.86} & Solid Plate & 22.1 & 20.975 & 36.83 & 16.76 & 18.42 & slippage \\
\hline & & $\begin{array}{c}\text { Biaxial } \\
\text { Geogrid }\end{array}$ & 93.195 & 24.11 & 150.55 & 16.87 & 77.66 & slippage \\
\hline & & ICB-GGR & 142.245 & 25.56 & 229.78 & 16.77 & 118.54 & slippage \\
\hline \multirow[t]{2}{*}{81.75} & \multirow[b]{2}{*}{88.11} & Solid Plate & 47.088 & 16.32 & 78.48 & 16.77 & 39.24 & slippage \\
\hline & & $\begin{array}{c}\text { Biaxial } \\
\text { Geogrid }\end{array}$ & 110.36 & 20.145 & 178.27 & 16.97 & 91.97 & slippage \\
\hline
\end{tabular}
in the first test carried out on the ICB-GGR, the failure was noticed to be by arching and the unfixed rear part of the box acted as a roller support as it lifted up about $1 \mathrm{~cm}$. Hence, the rear part was fixed after that to prevent arching on the next tests.

Table (1): Summary ofresults of thePull-Out Tests.

The percentages of improving the soil characteristics and the pull-out resistance when using Biaxial Geogrid and ICB-GGRcompared with the SolidPlate as a control case are tabulated in columns (3), (4)and (6) of Table (2). Columns (7), (8)and (9) in the same table show the percentages of improvement resulted in case of

\begin{tabular}{|c|c|c|c|c|c|c|c|c|}
\hline $\begin{array}{c}\sigma_{\mathrm{n}}\left(\mathrm{kN} / \mathrm{m}^{2}\right) \\
(1)\end{array}$ & $\begin{array}{c}\text { Type of GGR } \\
(2)\end{array}$ & $\begin{array}{l}\% \mathrm{P} \\
(3)\end{array}$ & $\begin{array}{l}\% \mathrm{Q} \\
(4) \\
\end{array}$ & $\begin{array}{l}\% \gamma \\
(5)\end{array}$ & $\begin{array}{c}\% \tau_{\text {ult }} \\
(6)\end{array}$ & $\begin{array}{l}\% \mathrm{P} \\
(7) \\
\end{array}$ & $\begin{array}{c}\% \mathrm{Q} \\
(8)\end{array}$ & $\begin{array}{c}\% \tau_{\text {ult }} \\
(9)\end{array}$ \\
\hline \multirow[t]{2}{*}{33.61} & Biaxial Geogrid & 200 & 190.76 & 5.12 & 200 & & & \\
\hline & ICB-GGR & 362.5 & 348.26 & 6 & 362.5 & 54.16 & 54.14 & 54.17 \\
\hline \multirow[t]{2}{*}{60.86} & Biaxial Geogrid & 321.7 & 308.8 & 5.44 & 321.7 & & & \\
\hline & ICB-GGR & 543.6 & 523.9 & 4.81 & 543.6 & 52.63 & 52.63 & 52.64 \\
\hline 88.11 & Biaxial Geogrid & 134.4 & 127.15 & 6.06 & 134.38 & & & \\
\hline
\end{tabular}
using theICB-GGR in comparison with the Biaxial Geogrid. Column (5) shows the percentage of densification of the soil after testing in compared with the original density before testing.

Table (2):Percentages of the Improvement caused by the Biaxial Geogrid and the ICB-GGRcompared with the results of the SolidPlate. 


\subsection{Average Density}

\section{Analysis and Discussion of Tests Results}

The interlocking between the geogrid apertures and the sand particles is the main cause of densifying the sand by minimizing the lateral movement of the particles. Adding the interlocking effect between the cogsand the sand particles resulted in the increase of the final soil density after testing. That is why the highest increase of the value of the averagedensity of sand after testing is noticed in case of using the ICB-GGRwith an increase of about $(5.41 \%)$ than the values recorded before testing, as shown in Table (2). Then comesthe density in case of using the Biaxial Geogrid with an increase of $(5.28 \%)$. The lowest value of the sand densityafter testing was recorded in case of using the Solidplate with an increase of $(4.63 \%)$.

\subsection{Friction Angle of Soil-Geogrid Interface and Friction Factor}

When calculating the friction angle of a soil-geogrid interface $\delta$, the highest valuewas recorded in case of using the ICB-GGR and it is nearly $64.76^{\circ}$. Then came the Biaxial Geogrid with $\delta=51.24^{\circ}$. The lowest value was recorded when using the Solid Plate with a value of $22.27^{\circ}$. It is obvious that the value of $\delta$ in case of using the ICB-GGR is $18.78 \%$ higher than that obtained in case of using the Biaxial Geogrid.

According to Mosallanezhad et al. [11] the maximum value of friction factor $\alpha$ may exceed the regular value of 1 , which usually recorded in pull-out polymeric gegrid tests. The obtained calculated values of friction factor are $\alpha_{\text {Solid Plate }}=0.77, \alpha_{\text {Biaxial Geogrid }}=2.35$, and $\alpha_{\text {ICB-GGR }}=4$. The percentage of increase in the factor $\alpha$ could be achived in case of using the ICB-GGR and is nearly $70 \%$ over the factor obtained when using the Biaxial Geogrid.

\subsection{Front Displacement}

Fig. (8) shows that, as the normal pressure acting on the three tested prototypes increases, the maximum front displacements before failure decrease.For the eight tests with slippage failure, the tests were ended when the leap reading was recorded.That leap appears obviously in Fig.(8-a,b,c,d).The behaviour of the extra test for the ICB-GGR is shown in Fig (8-a) at normal stress of $25.16 \mathrm{kN} / \mathrm{m}^{2}$.As shown in Fig. (9) the maximum front displacement decreases with the increasing of the normal stress acting on the three prototypes.
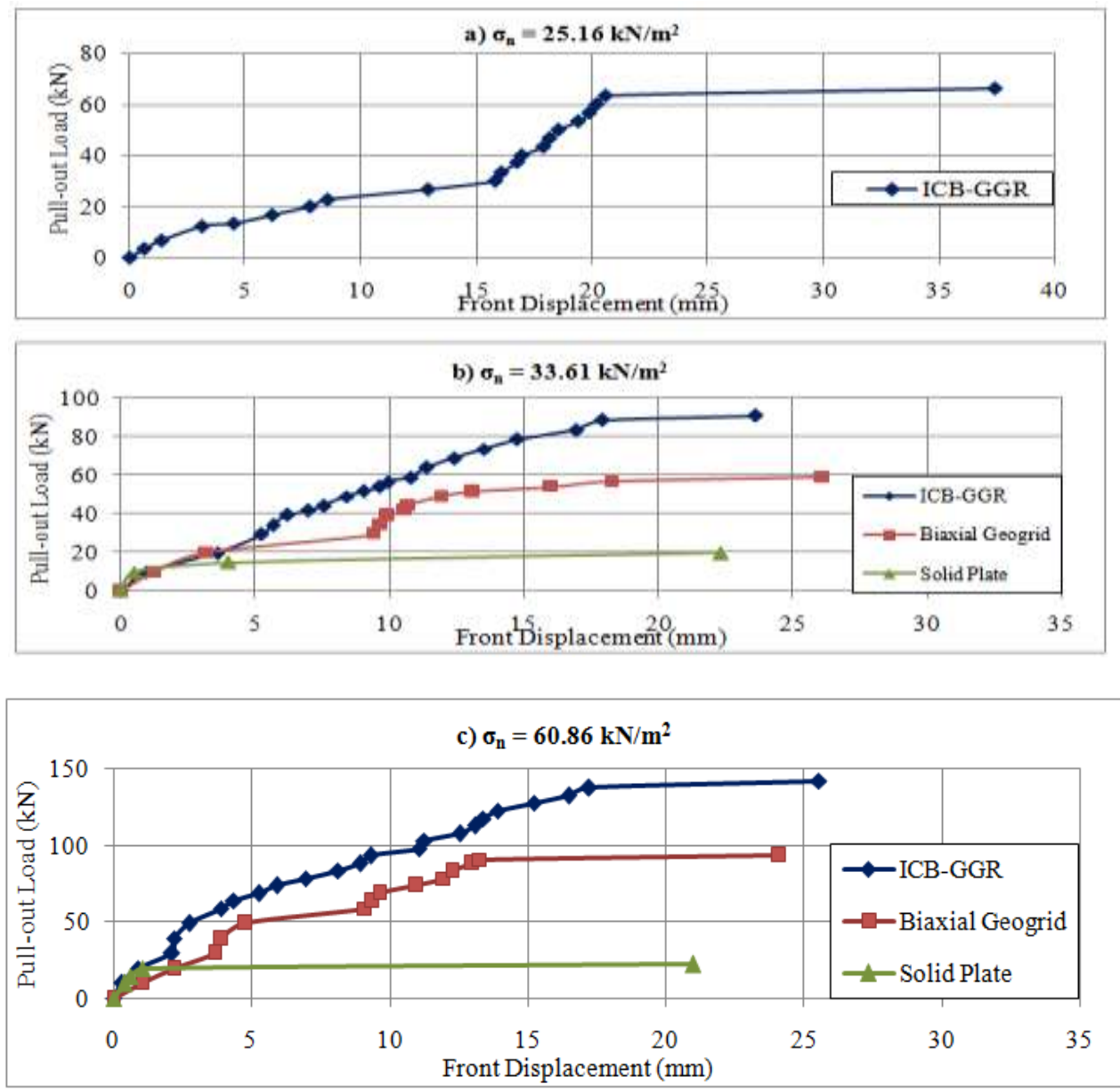


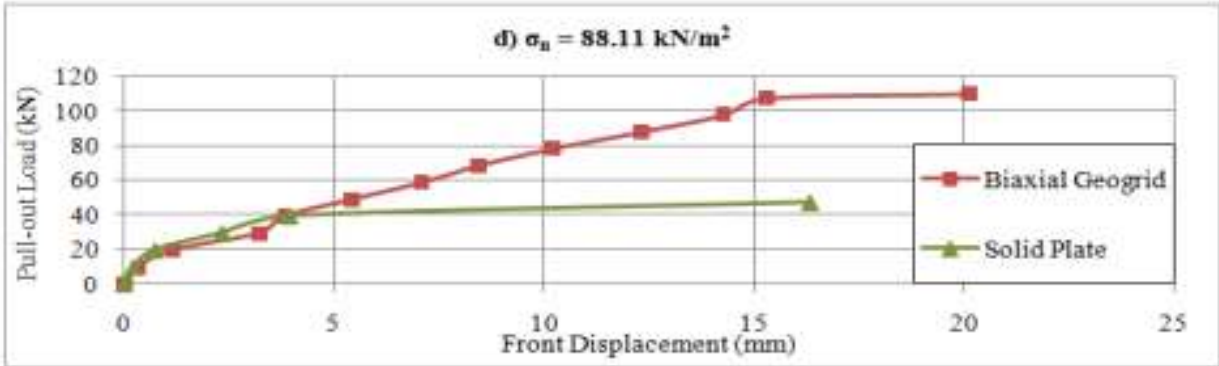

Figure (8):The relationship between the pull-out load and the front displacement for the three geogrids.

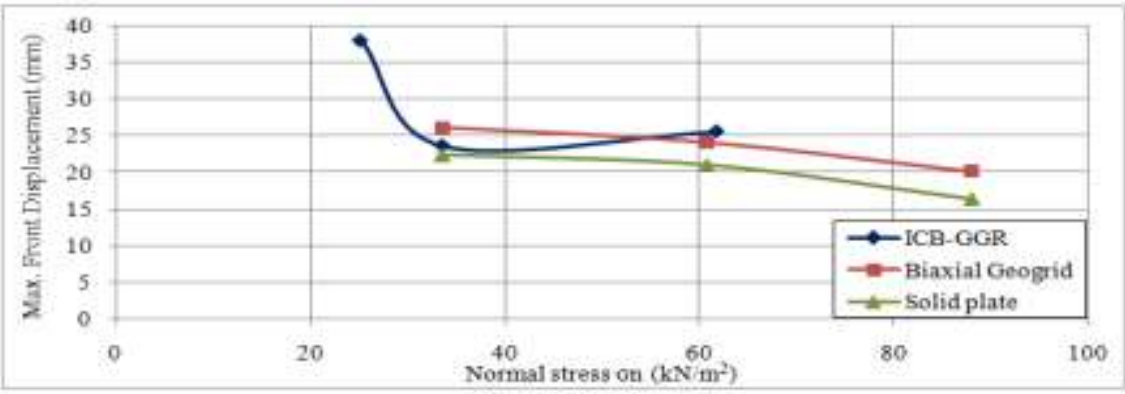

Figure (9):Effect of using different values of normal pressure on the max. front displacement.

\subsection{Pull-Out Resistance}

The pull-out resistance of each case was calculated according to prEN 13738 [11] and the results were plotted as shown in Fig. (10). It is obvious that at a normal stress of $60.86 \mathrm{kN} / \mathrm{m}^{2}$, thehighest value of the pullout resistance is obtained in case of using the ICB-GGR and it is about 50\% higher than that obtained when using the Biaxial Geogrid. Also, as expected, itcan be noticed that for all geogrids, the pull-out resistanceincreases as the normal stress increases.

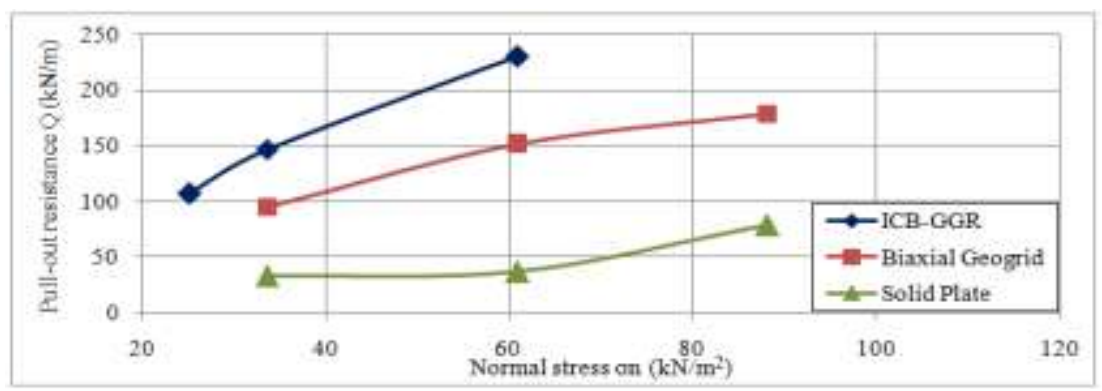

Figure (10):Effect of using different types of geogrids on the pull-out resistance.

\subsection{Interface Shear Strength}

As shown in Fig. (11)for the three prototypes, the interface shear strength increases with the increasing of the normal stress. The interface shear strength in case of using the ICB-GGR is higher than that obtained when using the Biaxial Geogrid by about 50\%. This value represents the percentage of the cogs contribution in resisting shear, as the other dimensions of the both geogrids are equivalent. It can be noticed also thatthe shear strength for the Solid Plate had the least average value with only $24.53 \mathrm{kN} / \mathrm{m}^{2}$.

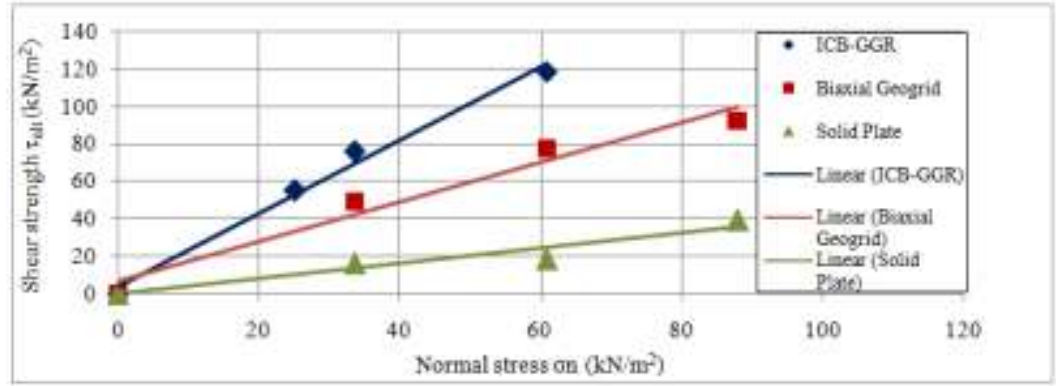

Figure (11): Effect of using different types of geogrids on the shear strength. 


\section{Conclusion}

Anewinvented shape of geogrid with cubic cogs is propsed in this study. The new geogrid is denominated as the ICB-GGRand it could be successfully testedin the laboratory using a pull-out testing device that was built especially for this purpose. The results achieved from testing the ICB-GGR were compared with those obtained from testing the conventional Biaxial Geogrid in the same pull-out testing device.The main conclusions drawn from these tests can be summarized as follows:

- The highest values of pull-out resistance were obtained in case of reinforcing the tested sand with thenew proposedICB-GGRand they are about 50\% higher than these obtained when using the conventional Biaxial Geogrid.

- The shear resistance value achieved when using the new proposed ICB-GGR superior the shear resistance value achieved when using the Biaxial Geogrid by about $50 \%$.

- The maximum values of the achieved pull-out capacity in case of using the proposed ICB-GGR are about 50\% higher than these achieved when using the conventional Biaxial Geogrid and about $365 \%$ more than the Solid Plate.

- The average percentage of cogs contribution inresisting shear is 50\%. This percentage represents also the value of superiorty of the ICB-GGR over the Biaxial Geogrid in resisting shear forces.

- The friction angle between the proposedICB-GGR and the sandis higher than that between the sand and the Solid Plate by about 42.49 degrees, and is higher than that between the conventional Biaxial Geogrid by about 13.52 degrees.

\section{References}

[1] S.K. Shukla, and J.-H. Yin, Fundamentals-of-Geosynthetic-Engineering, (Taylor \& Francis Group, London, UK, 2006).

[2] J.P. Giroud, Geogrid Jubilee Symposium in London, 2009.

[3] M.I.M. Pinto, Discussion of Applications of geosynthetics for soil reinforcement, Ground Improvement, 7(2), 2003, 61-72

[4] A-A.A. Senoon, and O.A. Farghal, Influence of the confinement, soil density, and anchorage length of reinforcement on soil geogrid interaction, Proc. 1st ICCES1 Conf. of Civil Engineering Science, Assiut University, Assiut, Egypt, 2003, $232-241$.

[5] A. Duszynska, A. F. Bolt, Pullout tests of geogrids embedded in non-cohesive soil, Archives of Hydro-Engineering and Environmental Mechanics,51(2), 2004, 135-147.

[6] R.M. Koerner, Designing with geosynthetics (Englewood Cliffs, NJ: Pearson Prentice, 2005).

[7] A.H. Abdel-Rahman, M.A-M. Ibrahim, and A.K. Ashmawy, Utilization of a large-scale testing apparatus in investigating and formulating the soil/geogrid interface characteristics in reinforced soils, AJBAS, Australian Journal of Basic and Applied Sciences, 1(4), 2007, 415-

[8] C.W. Hsieh, G.H. Chen, and J.H. Wu,The shear behavior obtained from the direct shear and pull-out tests for different poor graded soil-geosynthetic systems, Journal of GeoEngineering, 6(1), 2011, 15-26.

[9] N. Moraci, and G. Cardile,Deformative behaviour of different geogrids embedded in a granular soil under monotonic and cyclic pull-out loads, Geotextiles and Geomembranes, 32(3), 2012, 104-110.

[10] M. Mosallanezhad,M.C. Alfaro, N. Hataf, S.H. Sadat Taghavi, Performance of the new reinforcement system in the increase of shearstrength of typical geogrid interface with soil,Geotextiles and Geomembranes,44, 2016, 457- 462.

[11] ASTM. Annual books of ASTM Standards, Construction: Soil and Rock (I) (American Society for Testing and Materials, Philadelphia, PA, 2006) D 4439.

[12] prEN 13738, Geotextiles and Geotextile-Related Products, Determination of Pullout Resistance in Soil, 1999. 